\title{
STUDENT REFLECTIONS ON NEEDS FINDING IN COMMUNITY-BASED DESIGN WORK
}

\author{
Loweth, Robert P.; Daly, Shanna R.; Sienko, Kathleen H.; Liu, Jiangqiong \\ University of Michigan
}

\begin{abstract}
Reflection is an important component in design skill development that helps designers better understand their design problem, develop better solutions, and improve their design approaches. This study explored the information that a student design team reflected on as part of a needs finding experience and the outcomes from these reflections. During the needs finding experience, the team exhibited reflection-inaction behavior as they used available data to form and iterate on explanatory hypotheses about potential community needs. After the needs finding experience, the team exhibited reflection-on-action behavior as they drew connections between their interview approaches and stakeholder responses and discussed changes they might make in the future. The team also identified situations where contextual factors of the stakeholder impacted their interviews, but during these reflections did not indicate how they might adapt their approaches to account for such factors in the future. These findings show that student designers can use reflection as a tool to improve their needs finding process but would benefit from pedagogical structures that might help them reflect more effectively.
\end{abstract}

Keywords: Reflective practice, Needs finding, Collaborative design, Decision making, Design education

Contact:

Loweth, Robert Pierpont

University of Michigan

Mechanical Engineering

United States of America

rloweth@umich.edu

Cite this article: Loweth, R.P., Daly, S.R., Sienko, K.H., Liu, J. (2019) 'Student Reflections on Needs Finding in Community-Based Design Work', in Proceedings of the 22nd International Conference on Engineering Design (ICED19), Delft, The Netherlands, 5-8 August 2019. DOI:10.1017/dsi.2019.61 


\section{INTRODUCTION}

Reflection - "intellectual or affective activities in which individuals engage to explore their experiences in order to lead to new understandings and appreciations" (Boud et al., 1985, p. 19) - is an important component in design skill development. Reflection allows designers to translate their design experiences into insights, which can help them (1) better understand the design problem, (2) develop better solutions, and (3) improve their design approaches. Previous descriptions of reflection behavior related to design have described two main types of reflection: reflection-in-action and reflection-on-action (Kolb, 1984; Schön, 1983, 1992). During reflection-in-action, designers generate design "moves" - hypotheses about the design problem or conjectures about potential solutions. By exploring the consequences of these "moves," designers iterate on their understanding of their specific design problem while still having the opportunity to adjust their design approach (Dong and MacDonald, 2017; Schön, 1983, 1992; Stompff et al., 2016; Valkenburg and Dorst, 1998). By comparison, reflection-on-action involves meaning-making through the translation of concrete observations or experiences by the designer into abstract generalizations about these experiences (Bray et al., 2000; Heron and Reason, 1997; Kolb, 1984). In particular, reflection-on-action relates to learning and skill building because, while the designer no longer has the opportunity to modify their past experience, these abstract generalizations form a basis for the designer to revise their actions in future similar situations (Adams et al., 2018; Bray et al., 2000; Brockbank et al., 2002; Heron and Reason, 1997; Kolb, 1984). Notably, previous research on reflection-in-action (Schön, 1983, 1992) and reflectionon-action (Bray et al., 2000; Kolb, 1984) has in both cases emphasized the role of information exchange between the designer and design situation for stimulating reflection behavior in the designer. During reflection-in-action, this information exchange helps designers understand the consequences of previous design moves and potential implications of future design moves. During reflection-on-action, this information exchange provides the basis for identifying both successes and errors, and subsequently learning from the experience. In both cases, the designer must be able to perceive and interpret the information they are receiving from the design situation. Otherwise, the designer may not be able to derive practical insights during reflection. Models for these two types of reflection are shown in Figure 1.
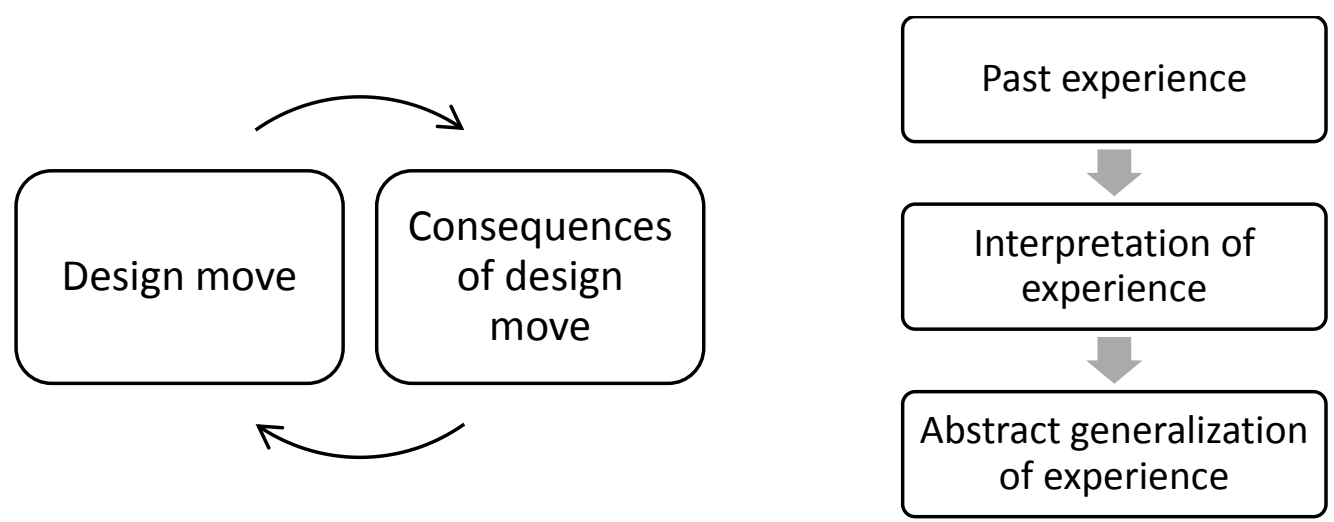

Figure 1. Models for reflection-in-action (left) and reflection-on-action (right)

The primary focus of this study is reflection in the context of "needs finding," or discovering potential design problems through organized research (Patnaik and Becker, 1999; Zenios et al., 2010). During needs finding activities, designers are still in the process of converging on a framing of the problem that will enable them to implement a potential solution (Dorst, 2015; Dym et al., 2005; Schön, 1983; Zenios et al., 2010). However, needs finding is inherently ambiguous and open-ended and involves collecting information from a variety of data sources that often may be in conflict. In these situations, it can be difficult to prioritize information and determine how best to proceed with the design project (Mohedas et al., 2014a, 2014b; Zenios et al., 2010). Reflection can play an important role in translating data from stakeholders into insights that can help the designer iterate on their understanding of the design problem (Schön, 1983). However, this translation requires that designers can interpret the information they receive from needs finding activities, usually based on their background and previous experiences (Bucciarelli, 1994; Dorst and Cross, 2001; Schön, 1992). In cases where designers struggle to interpret their needs finding data, reflection may not lead to useful insights (Mohedas et al., 2014a; Schön, 1983). 
The role of reflection in defining and clarifying design problems during needs finding activities has specific implications for student design processes and learning. Engineering students encounter open-ended needs finding situations in both curricular and co-curricular settings (Sienko et al., 2018). Previous studies have shown that these students often struggle when interacting with stakeholders and translating stakeholder data into insights about needs and requirements (Luck, 2007; Mohedas et al., 2014a). To combat these challenges and make these open-ended experiences more valuable for students, instructors likely need to provide additional structures or training for needs finding. Studying student reflections provides detailed information about how students interpret open-ended needs finding experiences and what they may be learning from these experiences as a result (Bray et al., 2000; Heron and Reason, 1997; Kolb, 1984). These descriptions may reveal specific gaps that could be addressed through the development of pedagogical interventions to improve student processes and learning.

\section{METHODS}

\subsection{Research questions}

This study focused on the information that engineering students reflect on when engaged in a needs finding experience, the relationships between these reflections and outcomes from the experience, and content that is missing from these reflections that may be important for the design project. The research questions that guided this study were:

1. What information did participants reflect on during their needs finding experience? What were the outcomes from these reflections?

2. What information did participants reflect on after their needs finding experience? What were the outcomes from these reflections?

3. What information from the needs finding experience did participants struggle to generalize during post-experience reflections?

\subsection{Design context}

This study followed a team of students at a large Midwestern university who planned and conducted a week-long needs finding experience in a rural South American community. Team members were part of an undergraduate co-curricular organization focused on medical device design for low-resource settings. This needs finding experience was the team's first visit to the community, and participants hoped that needs identified as part of the trip might form the basis for new design projects. Prior to the trip, the team completed training at their university in conducting design observations, conducting needs assessments, and developing needs statements. Once in the field, the team spent several hours each day conducting observations of community medical centers and interviewing local villagers. They were aided in this data collection by two primary community partners (hereafter referred to as "the guides"), who acted as a liaison between the team and the community. Each night, the team re-convened for group reflections to discuss the data that each team member had collected that day and plan next steps.

\subsection{Participants}

Demographic information on the twelve participants are shown in Table 1 (names are pseudonyms). Qualitative work often has small sample sizes to allow for in-depth investigation (Borrego et al., 2009); this sample size is in alignment with other qualitative reflection studies (Schön, 1992; Valkenburg and Dorst, 1998). Participants generally had one to three semesters of curricular design experience and/or six to eighteen months of co-curricular and/or internship design experience. The one exception was the graduate student participant, who had completed eight semesters of coursework related to engineering design and had two years of relevant co-curricular and internship experience. None of the participants had substantial previous experience planning or conducting needs finding activities in their design work, although one of the two team leads, Alli, had some previous experience conducting design interviews. As such, the team's relevant knowledge on needs finding came primarily from their pre-trip training.

\subsection{Data collection}

Data collected as part of this study included individual reflection journals that each team member completed at the end of each day, audio recordings of the group's nightly discussions, and field notes from 
the team's data collection experiences. Upon return from the trip, additional data about participant interpretations of their data collection and needs finding experiences were collected through retrospective interviews. Recordings of nightly discussions and post-trip interviews, which included over 12 hours of audio data in total, were transcribed to facilitate data analysis.

Table 1. Summary of participants

\begin{tabular}{|c|c|c|c|c|c|}
\hline Pseudonym & Year & Sex & Ethnicity & Major 1 & Major 2/Minor \\
\hline John & Freshman & $\mathrm{M}$ & Caucasian & Public Health & \\
\hline $\begin{array}{l}\text { Emma } \\
\text { (Lead) }\end{array}$ & Master's & $\mathrm{F}$ & Caucasian & Biomedical Engineering & \\
\hline Isabelle & Sophomore & $\mathrm{F}$ & Asian & Chemical Engineering & \\
\hline Sophie & Freshman & $\mathrm{F}$ & Asian & Biomedical Engineering & \\
\hline Jill & Sophomore & $\mathrm{F}$ & Caucasian & Industrial Engineering & $\begin{array}{l}\text { International Minor } \\
\text { for Engineering }\end{array}$ \\
\hline Stephanie & Junior & $\mathrm{F}$ & $\begin{array}{l}\text { Asian/ } \\
\text { Caucasian }\end{array}$ & Biomedical Engineering & American Culture \\
\hline Chloe & Freshman & $\mathrm{F}$ & Caucasian & Biomedical Engineering & \\
\hline Maria & Freshman & $\mathrm{F}$ & Hispanic & Public Health & Spanish \\
\hline Emily & Sophomore & $\mathrm{F}$ & $\begin{array}{l}\text { Asian/ } \\
\text { Caucasian }\end{array}$ & Mechanical Engineering & Music \\
\hline Melissa & Freshman & $\mathrm{F}$ & Asian & Biomedical Engineering & Creative Writing \\
\hline Arya & Freshman & $\mathrm{F}$ & Asian & Electrical Engineering & Business \\
\hline Alli (Lead) & Junior & $\mathrm{F}$ & Caucasian & Mechanical Engineering & $\begin{array}{l}\text { Multidisciplinary } \\
\text { Design }\end{array}$ \\
\hline
\end{tabular}

\subsection{Data analysis}

Transcriptions of the nightly discussions were analyzed by two coders to identify types of information that stimulated team reflections, as well as outcomes from these reflections. This analysis resulted in a set of themes linking types of information to specific reflection outcomes (Creswell, 2003; Miles et al., 2014; Patton, 2015). These themes were verified through comparison with participant responses in post-trip interviews and individual reflection journals (Borrego et al., 2009; Creswell, 2003; Leydens et al., 2004). Once themes were established, they were sorted according to the three research questions of this study. Reflection behaviors that the team exhibited earlier in the trip and that led to immediately actionable insights were coded as reflection-in-action. Behaviors that occurred later in the trip, once the team no longer had the opportunity to change their approach, were coded as reflection-on-action.

\section{FINDINGS}

Findings are presented below in three main sections, mirroring the three research questions of this study. The first section outlines the information that the team reflected on during the needs finding experience. The second section describes the information that the team reflected on after this experience. Finally, the third section explores information that the team struggled to generalize during reflections.

\subsection{Information the team reflected on during their needs finding experience}

During their needs finding experience, the team often exhibited reflection-in-action behavior when trying to identify potential community needs and subsequently refine their interpretations of those needs. This reflection-in-action behavior tended to follow one of two different patterns, described below.

Theme: The team reflected on the data they had collected from interviews and observations. They compared these data to information from their guides about the people and community to better understand the dimensions of potential community needs.

During nightly reflections, the team synthesized the data they had collected thus far into explanatory hypotheses about potential community needs. These explanatory hypotheses represented reflection-inaction design moves towards clarifying the design problem. Exploring the implications of these design moves helped the team understand additional dimensions of their hypothesized needs (Dong and MacDonald, 2017; Schön, 1983, 1992). One way that the team explored their ideas about community needs 
was by comparing these proposed needs to the background information about the people and community provided by the team's guides. This act of comparison is illustrated in the following excerpt:

Alli: I'd be interested to see more of the government programs and how effective they are, because it seems like the government here is doing a lot. Everything that we ask about, it's like, "There's a government program for this. There's an incentive for this." It seems like they're trying to do a lot. I'm just curious if they're at all effective...

Sophie: Yeah, I remember when [the guide] was talking about dental health, he said that a lot of [kids] brush their teeth because they wanna be like celebrities, not because of health.

Isabelle: Yeah. And the government is providing children with vaccines, which is also really interesting. They go to the communities, he said, and that's really awesome.

Melissa: But he also says sometimes the clinics don't have the medication, so even though it's theoretically free, sometimes it won't come for months.

Isabelle: And they don't really treat malaria. That's the one they don't fully treat.

Jill: I thought he said they treated all of the public health hazards.

Alli: Yeah. All public health is free. All public health, like vaccinations, medication, things like that are free. It's just whether they're actually gonna have medicine when you need it, is what it sounds like. (Night 2 Group Discussion)

Here, Alli proposed that the effectiveness of government programs in the community might not have matched the effort that the government seemed to be investing. This statement represented an explanatory hypothesis about a potential community need. Sophie, Isabelle, and Melissa then provided feedback on this hypothesis based upon information received from the guides. Specifically, they highlighted that factors such as culture ("...they wanna be like celebrities...") and availability ("...even though it's technically free...") also substantially influenced this potential need. Jill then challenged this assertion, based upon her interpretation of what their guide had told them. Finally, Alli used this feedback to clarify her position, synthesizing the information from the guides into her earlier proposal: the effectiveness of government programs potentially related to issues of availability, meaning that the availability of medicine may have been the more fundamental need. This exchange represented a complete reflection-in-action cycle: the team introduced a potential need based on their data, introduced information from the guide in response, and used this information to iterate on the potential need.

Theme: The team reflected on the reasons behind differences in stakeholder responses to better understand the range of perspectives relating to potential community needs.

Reflection-in-action behavior also occurred when the team attempted to reconcile conflicting viewpoints across stakeholders. The team generated explanatory hypotheses for why these conflicts emerged and discussed implications of these conflicts for their data. The following excerpt shows how this reflection helped the team better understand the range of perspectives related to potential community needs:

Emma: So, we're gonna switch over to the other community... That's really interesting that you guys are talking about the government. We heard the complete opposite.

Melissa: There was also an explanation for that... This is the same lady that we were talking to yesterday, by the way, that we all met.

John: She said that [the government] doesn't do anything for the community...

Melissa: She said that [the villagers] had to care for themselves first.

John: Yeah, there's no coordinated effort.

Melissa: Also, she's on the religious outskirts of the community to some extent, everybody else is [a different religious group]. (Night 3 Group Discussion)

Following up on the conversation from the day before, a few of the team members talked to community leaders about the effectiveness of government programs. In general, they found that there were several issues, such as crime, for which current efforts seemed to be highly effective. However, Emma challenged the accuracy of this information by referring to another stakeholder who held an opposing view. Faced with this contradiction, Melissa and John provided an explanatory hypothesis ("...she's on the religious outskirts..."). The implication of this hypothesis was that, given the religious minority status of the woman in question, there may have been reason to doubt that her views of the government were widely held by other community members. This exchange also represented a complete reflection-in-action cycle: the team introduced the perspective of a specific stakeholder, introduced reasons why the stakeholder may have held that perspective, and used this information to evaluate the relevancy of that stakeholder's perspective for characterizing a potential community need. From this conversation, the team also realized that they needed to account for diverse perspectives when collecting data. 


\subsection{Information the team reflected on after their needs finding experience}

The themes above show how the team demonstrated reflection-in-action behavior during their needs finding experience. Towards the end of their trip, the team also began to demonstrate reflection-on-action behavior as well. Reflection-on-action discussions centered around the team's approaches to interacting with stakeholders during earlier data collection and lessons learned from these interactions.

Theme: Team members reflected on the content of stakeholder responses as a function of their individual interviewing approach, identifying how specific aspects of these approaches may have influenced the ways that stakeholders responded.

As participants interacted with more stakeholders, they began to recognize the ways that their interview approach impacted stakeholder responses. These reflections aligned with reflection-on-action behavior (Bray et al., 2000; Heron and Reason, 1997; Kolb, 1984): the team developed consistent interpretations of their interview experiences that translated into generalizations about how the team should conduct future interviews. Members of the team identified two key challenges that affected stakeholder responses. First, team members found that stakeholders did not always understand the language that the students were using when asking questions, as illustrated by the following excerpt:

Maria: But we also had a hard time trying to get her to understand "cervical [screening]," there might have been some misinterpretation. She might have felt like we meant something invasive, like surgery or something... so maybe that was a miscommunication.

Emma: They also don't seem to understand that women's health is a thing, that cervical screenings or even pap smears are important. When they talk about family planning, they talk about family and having babies and when we asked her later about other things, she was talking about a woman after pregnancy. It's all about pregnancy... (Night 5 Group Discussion)

In this case, the team had identified women's health issues, particularly related to a lack of cervical screenings, as a potentially important need in the community. However, when trying to follow up on this need, members of the team found that one of their stakeholders seemed to equate women's health with pregnancy. The team members interpreted this difficulty in terms of their own interview approach: they were using language related to cervical screenings and women's health that may have been unfamiliar to the stakeholder. This explanation further translated into an abstract generalization about the broader team's interview approaches, namely that there was a relationship between the language the team used during stakeholder interviews and the stakeholder's comprehension of the team's questions.

Second, the team found that their interview structures also influenced stakeholder responses:

Stephanie: He said, "I would drink it over river water," but none of the other people said that.

Jill: $\quad$ Then we asked him what the biggest problem in his opinion was and he said the water. We did ask him that at the end though.

Stephanie: After asking all about water, though.

Alli: I think that was a really leading question. (Night 5 Group Discussion)

Originally, the team had structured their interviews so that big-picture summary questions, such as biggest problems in the community, were asked at the end of the interview. However, members of the team noticed that there was a connection between the stakeholder's final response about overarching community needs and earlier questions in the interview that had been focused primarily on water quality ("... after asking all about water..."). As before, team members interpreted their observations from this interview experience in terms of how they had conducted the interview: their earlier questions had set up the stakeholder's final response. This interpretation led the team members to conclude that structuring an interview around a focused topic with broader questions at the end might lead the stakeholder to answer these broader questions in an inauthentic way. Once Stephanie, Jill, and Alli presented this generalization of the experience, other members of the team realized that they might also have been leading their stakeholders with their interview structures. Both examples described here demonstrate reflection-on-action behavior: members of the team experienced a certain stakeholder response, interpreted that response in terms of their interview approach, and translated this interpretation into an abstract generalization of how to approach future interviews. These generalizations represent specific learning gains experienced by the whole team about conducting stakeholder interviews.

\subsection{Information that the team struggled to generalize}

The examples above show the team moving through all three steps of reflection-on-action: experience, interpretation, and abstract generalization. However, there were also situations where the team interpreted 
an experience but did not translate this interpretation into a broader generalization about the experience. In other words, there were situations where the team identified an unusual stakeholder interaction, discussed a potential cause, but did not indicate what they might change in the future.

Theme: When team members encountered surprising or unusual stakeholder responses that they could not clearly link to their interview approach, the team's reflections on these experiences included little discussion of implications or future changes.

Like the earlier examples of reflection-on-action, these reflective exchanges began with identification of an unusual stakeholder response experienced while conducting interviews. However, the team did not generate abstract generalizations from these experiences. Instead, the team explained their observations in terms of qualities inherent to the stakeholder rather than as reactions to specific aspects of the team members' approach. The following excerpt provides an example of this type of exchange:

Maria: We did ask them if they had any idea how much water they drank, or how much the children drink. None of them really had an idea. The last woman that we talked to, she kind of had an indication. Five liters. Which is just a lot.

Jill: I don't think she really knew what a liter was.

Maria: But they don't keep track of how hydrated they're staying.

Alli: And most of them said that they just take a handful whenever they're thirsty. The kids drink when they're thirsty. There's no reason to watch or monitor it. (Night 5 Group Discussion)

Here, Maria and Jill indicated that their stakeholder's claim to drink five liters of water a day seemed unlikely. This initial description resembled the woman's health example described above in that team members identified a challenge that they had encountered during an interview. However, in this case the challenge was explained as relating to stakeholder knowledge ("I don't think she really knew what a liter was") rather than to the team members' approach. The team simply noted that the information was likely inaccurate and thus did not explore implications of the response for the team's interviewing approaches. In another instance, the team encountered a situation where one of their stakeholders suddenly became unresponsive. In this case as well, the team provided a potential explanation in terms of qualities of the stakeholder without discussing how this response might have related to the team members' approach:

Jill: We also asked him if there was anything that the government could do to improve the quality of life and he said he couldn't think of anything.

Stephanie: He just looked the other way. He didn't even respond. He seemed really uncomfortable, like didn't want to answer.

Alli: Or he didn't understand the question. Like something just wasn't connecting.

Stephanie: He wasn't making eye contact with us. It was very weird.

Isabelle: The whole time, or just at that question?

Stephanie: No, just at that question.

Emma: He might have also grown up in a different time, when [the country] was being controlled by a different government. He might not have been okay to talk about the government... But that's definitely interesting. (Night 5 Group Discussion)

As with the earlier example, the team commented on the unusual reaction, provided a potential explanation in terms of individual stakeholder characteristics ("...may have grown up in a different time..."), and then moved on without discussing the potential implications of the stakeholder's reaction. In both cases, the team recognized that contextual factors of the stakeholder affected the interview. However, unlike with the earlier examples involving the team's language and interview structures, the team struggled in this case to interpret the influence of contextual factors in such a way that they might produce generalizations about the experience and modify their interview approaches in the future.

\section{DISCUSSION}

\subsection{Student reflection-in-action and reflection-on-action in needs finding}

The examples above show how the reflection-in-action and reflection-on-action behaviors of the team related to specific types of information and experiences. During nightly discussions, reflection-in-action behavior helped the team iterate on their conception of community needs and identify new avenues to explore. This process of generating explanatory hypotheses and introducing known information in response mirrored the cycle of design moves described in the reflection-in-action literature (Dong and MacDonald, 
2017; Schön, 1983, 1992; Stompff et al., 2016). One interesting aspect of this study was that the team's reflection-in-action behavior occurred in a group setting. Schön's $(1983,1992)$ initial description of reflection-in-action implied individual reflection, with the implication that designer perspective substantially influenced the direction of problem framing and solution generation (Bucciarelli, 1994; Dorst, 2015; Dorst and Cross, 2001). However, following more recent scholarship on group reflection-in-action (Dong and MacDonald, 2017; Stompff et al., 2016), we found that the individual who asked a question was usually not the same individual who introduced relevant information in response (see also Adams et al., 2018). These organic dialogues between team members were a primary driver of needs iteration. In part, these dialogues were spurred by the fact that the team had divided into two separate data collection groups who interacted with different stakeholders, thus necessitating information exchange during discussions. However, team members also challenged each other's assumptions about community needs in cases where team perspectives diverged. These dialogues thus mitigated the influence that one individual's personal perspective had on the framing of community needs and allowed for the introduction and comparison of many competing problem frames. The result was that the group's reflection-in-action behavior produced problem frames that were a synthesis of the team's different perspectives and different data collection experiences, although we cannot evaluate in this study how closely these synthesized descriptions of needs aligned with true community needs.

Furthermore, reflection-on-action on the team's interview approaches often inspired discussion on how the team might change their approaches in the future. During reflection-on-action exchanges, the team drew a link between their actions and specific outcomes from stakeholder interactions. The errors that the team identified, such as leading stakeholders to a conclusion and using language that the stakeholder did not fully understand, resemble other accounts of student designer struggles with conducting stakeholder interviews (Luck, 2007; Mohedas et al., 2014a). By identifying a causal link between action and outcome, the team could describe what they might change in the future, thus demonstrating learning through reflection (Bray et al., 2000; Brockbank et al., 2002; Kolb, 1984). Since the team had split into groups who each had unique experiences, reflection-on-action also provided an opportunity to compare experiences and learn as a team. As a result, all team members touched on the need to not ask leading questions during posttrip interviews, regardless of whether they were a member of the group who first recognized that their questions might be leading. The team thus reached a level of "propositional" or abstract knowing about certain aspects of interacting with stakeholders that might lead to "practical" knowing in the future (Adams et al., 2018; Bray et al., 2000; Heron and Reason, 1997; Kolb, 1984). Indeed, given observations by Luck (2007) and Adams et al. (2018), participants likely would have put some of these insights into practice during their needs finding trip had they had enough time to do so.

Finally, the team struggled to produce generalizations for experiences where contextual factors influenced stakeholder responses. The team interpreted these factors as a given rather than something to account for in their interview approaches. This explanation proved to be a barrier to developing broader generalizations about the experience: the team recognized the influence of contextual factors but did not reach the level of propositional knowing needed to translate experiences into learning gains and revised practice (Adams $e t$ al., 2018; Bray et al., 2000; Heron and Reason, 1997; Kolb, 1984). As such, only two participants during post-trip interviews mentioned the unusual interactions with stakeholders described in Section 3.3. In both cases, the participant observed those interactions directly. Prior research indicates a few potential reasons why the team struggled to recognize the connection between contextual factors and interview approach. First, identifying contextual factors may require a critical consciousness about the relationship between the practitioner and stakeholder that most undergraduate students are still developing (Abedini et al., 2012; Kumagai and Lypson, 2009; Leydens and Lucena, 2009). In addition, the team may have been small enough or homogenous enough in certain key ways such that the whole team might share certain assumptions (Bucciarelli, 1994; Dorst, 2015; Watkins et al., 2012). Finally, the team had limited time in the field, which proved just enough to recognize more salient issues such as the impact of word choice and question order. The team may not have had time to recognize the subtler influence of contextual factors on interviews, especially if they were not prepared to look for them.

\subsection{Limitations}

This study focused on an in-depth exploration of the reflections of a single team engaged in needs finding for a relatively short period of time. While these findings are not generalizable in a quantitative sense, the thick description presented here does provide a basis for comparison with other similar situations to identify elements that may be transferable (Borrego et al., 2009; Leydens et al., 2004). In addition, this 
study only had access to the team's reflections on their experiences, rather than direct data about the experiences themselves. As such, there may have been other experiences that the team did not discuss during their reflections that might also have impacted their approaches to their stakeholder interactions. Finally, the composition of this design team is unusual in the context of engineering, with 11 out of 12 members being female and with half the team also pursuing non-engineering double majors or minors. This unique composition may have influenced the ways that the team reflected as a group, particularly their willingness to challenge each other's assumptions and be challenged in return.

\subsection{Implications for design education and practice}

The findings from this study have several implications for future design pedagogy and practice. First, student designers can use reflection as a tool to improve their needs finding processes. For instance, the participants in this study used reflection to iterate on their understanding of their design problem and to identify ways to improve their data collection approaches in the future. However, these reflections were organic and largely unstructured, meaning that there was some serendipity in what information the team chose as reflection topics. This lack of structure led to a suboptimal outcome in that the team did not recognize the need to reflect on their data collection approaches until the trip was over. Future pedagogy could thus guide students in reflecting more intentionally and in a more time-sensitive manner so as to leverage the full power of reflections for improving their needs finding processes.

Second, the outcomes of reflection behavior are closely related to the designer's available information, so designers should conduct rigorous background research and map out relevant stakeholders in advance of needs finding activities. During reflection-in-action episodes, available information drove the team's explanatory hypotheses about community needs and the proposed implications of these hypotheses. While the quality of information is unclear in this case, especially since this information came almost entirely from the team's guides, it is easy to see how incorrect or biased information would have led the team to identify and refine needs that were in fact misaligned with the true needs of the community. This concern is particularly relevant in situations where the duration of needs finding activities is limited.

Finally, engineering students need pedagogical structures that can help them identify and interpret the influence of contextual factors during stakeholder interactions. The current design literature touches on best practices for accounting for stakeholder context (Aranda-Jan et al., 2016; IDEO, 2015; Kouprie and Sleeswijk Visser, 2009; Leydens and Lucena, 2009; Wood and Mattson, 2016); these best practices may provide language and structures to help students identify the role of contextual factors in stakeholder interactions and reflect on how they might account for these factors in the future.

\section{REFERENCES}

Abedini, N.C., Gruppen, L.D., Kolars, J.C. and Kumagai, A.K. (2012), "Understanding the effects of short-term international service-learning trips on medical students", Academic Medicine, Vol. 87 No. 6, p. 820. https://doi.org/10.1097/ACM.0b013e31825396d8.

Adams, R., Aleong, R., Goldstein, M. and Solis, F. (2018), "Rendering a multi-dimensional problem space as an unfolding collaborative inquiry process”, Design Studies, Vol. 57, pp. 37-74. https://doi.org/10.1016/j.destud.2018.03.006.

Aranda-Jan, C.B., Jagtap, S. and Moultrie, J. (2016), “Towards a framework for holistic contextual design for lowresource settings", International Journal of Design, Vol. 10 No. 3, pp. 43-63.

Borrego, M., Douglas, E.P. and Amelink, C.T. (2009), "Quantitative, qualitative, and mixed research methods in engineering education”, Journal of Engineering Education, Vol. 98 No. 1, pp. 53-66. https://doi.org/10.1002/j.2168-9830.2009.tb01005.x.

Boud, D., Keogh, R. and Walker, D. (1985), "Promoting reflection in learning: A model”, in Boud, D., Keogh, R. and Walker, D. (Eds.), Reflection: Turning Experience into Learning, RoutledgeFalmer, New York, NY, pp. 18-40.

Bray, J.N., Lee, J., Smith, L.L. and Yorks, L. (2000), Collaborative Inquiry in Practice: Action, Reflection, and Meaning Making, SAGE Publications, Thousand Oaks, CA.

Brockbank, A., McGill, I. and Beech, N. (2002), "Reflective learning in practice", in Brockbank, A., McGill, I. and Beech, N. (Eds.), Reflective Learning in Practice, Gower Publishing Company, Burlington, VT, pp. 18-28.

Bucciarelli, L.L. (1994), Designing Engineers, MIT Press, Cambridge, MA.

Creswell, J.W. (2003), Research Design: Qualitative, Quantitative, and Mixed Methods Approaches, 2nd ed., SAGE Publications, Thousand Oaks, CA.

Dong, A. and MacDonald, E. (2017), "From observations to insights: The hilly road to value creation", in Christensen, B.T., Ball, L.J. and Halskov, K. (Eds.), Analysing Design Thinking: Studies of Cross-Cultural Co-Creation, Taylor and Francis Group, London, UK, pp. 465-482. 
Dorst, K. (2015), Frame Innovation: Create New Thinking by Design, MIT Press, Cambridge, MA.

Dorst, K. and Cross, N. (2001), "Creativity in the design process: Co-evolution of problem-solution", Design Studies, Vol. 22 No. 5, pp. 425-437. https://doi.org/10.1016/S0142-694X(01)00009-6.

Dym, C.L., Agogino, A.M., Eris, O., Frey, D.D. and Leifer, L.J. (2005), "Engineering design thinking, teaching, and learning”, Journal of Engineering Education, Vol. 94 No. 1, pp. 103-120. https://doi.org/10.1002/j.21689830.2005.tb00832.x.

Heron, J. and Reason, P. (1997), “A participatory inquiry paradigm”, Qualitative Inquiry, Vol. 3 No. 3, pp. $274-294$. https://doi.org/10.1177/107780049700300302.

IDEO. (2015), The Field Guide to Human-Centered Design, IDEO.org, Canada.

Kolb, D.A. (1984), Experiential Learning: Experience as the Source of Learning and Development, Prentice-Hall, Englewood Cliffs, NJ.

Kouprie, M. and Sleeswijk Visser, F. (2009), “A framework for empathy in design: Stepping into and out of the user's life", Journal of Engineering Design, Vol. 20 No. 5, pp. 437-448. https://doi.org/10.1080/09544820902875033.

Kumagai, A.K. and Lypson, M.L. (2009), "Beyond cultural competence: Critical consciousness, social justice, and multicultural education", Academic Medicine, Vol. 84 No. 6, p. 782. https://doi.org/10.1097/ACM.0b013e3181a42398.

Leydens, J.A. and Lucena, J.C. (2009), "Listening as a missing dimension in engineering education: Implications for sustainable community development efforts", IEEE Transactions on Professional Communication, Vol. 52 No. 4, pp. 359-376. https://doi.org/10.1109/TPC.2009.2032383.

Leydens, J.A., Moskal, B.M. and Pavelich, M.J. (2004), "Qualitative methods used in the assessment of engineering education”, Journal of Engineering Education, Vol. 93 No. 1, pp. 65-72. https://doi.org/10.1002/j.21689830.2004.tb00789.x.

Luck, R. (2007), "Learning to talk to users in participatory design situations”, Design Studies, Vol. 28 No. 3, pp. 217242. https://doi.org/10.1016/j.destud.2007.02.002.

Miles, M.B., Huberman, A.M. and Saldana, J. (2014), Qualitative Data Analysis: A Methods Sourcebook, 3rd ed., SAGE Publications, Los Angeles, CA.

Mohedas, I., Daly, S.R. and Sienko, K.H. (2014a), "Design ethnography in capstone design: Investigating student use and perceptions", International Journal of Engineering Education, Vol. 30 No. 4, pp. 880-900.

Mohedas, I., Daly, S.R. and Sienko, K.H. (2014b), "Gathering and synthesizing information during the development of user requirements and engineering specifications”, 121 st ASEE Annual Conference and Exposition, Indianapolis, IN, June 15-18, 2014, ASEE.

Patnaik, D. and Becker, R. (1999), "Needfinding: The why and how of uncovering people's needs", Design Management Journal (Former Series), Vol. 10 No. 2, pp. 37-43. https://doi.org/10.1111/j.19487169.1999.tb00250.x.

Patton, M.Q. (2015), Qualitative Research and Evaluation Methods, 4th ed., SAGE Publications, Thousand Oaks, CA.

Schön, D.A. (1983), The Reflective Practitioner: How Professionals Think in Action, Basic Books, New York, NY.

Schön, D.A. (1992), "Designing as reflective conversation with the materials of a design situation", Research in Engineering Design, Vol. 3 No. 3, pp. 131-147. https://doi.org/10.1007/BF01580516.

Sienko, K.H., Young, M.R., Effah Kaufmann, E., Obed, S., Turpin, C., Danso, K.A., Opare-Addo, H.S., et al. (2018), "Global health design: Clinical immersion, opportunity identification and definition, and design experiences", International Journal of Engineering Education, Vol. 34 No. 2(B), pp. 780-800.

Stompff, G., Smulders, F. and Henze, L. (2016), "Surprises are the benefits: Reframing in multidisciplinary design teams”, Design Studies, Vol. 47, pp. 187-214. https://doi.org/10.1016/j.destud.2016.09.004.

Valkenburg, R. and Dorst, K. (1998), "The reflective practice of design teams", Design Studies, Vol. 19 No. 3, pp. 249-271. https://doi.org/10.1016/S0142-694X(98)00011-8.

Watkins, R., Meiers, M.W. and Visser, Y.L. (2012), A Guide to Assessing Needs: Essential Tools for Collecting Information, Making Decisions, and Achieving Development Results, The World Bank, Washington, DC.

Wood, A.E. and Mattson, C.A. (2016), "Design for the developing world: Common pitfalls and how to avoid them", Journal of Mechanical Design, Vol. 138 No. 3, p. 031101. https://doi.org/10.1115/1.4032195.

Zenios, S., Makower, J. and Yock, P. (Eds.). (2010), Biodesign: The Process of Innovating Medical Technologies, Cambridge University Press, Cambridge, UK.

\section{ACKNOWLEDGMENTS}

This material is based upon work supported by the National Science Foundation under Grant No. 1611687. Any opinions, findings, and conclusions or recommendations expressed in this material are those of the author(s) and do not necessarily reflect the views of the National Science Foundation. 